specimens of Adeona were captured. This curious Bryozoarian, of leaf-like shape and attached to a segmented stem, has sometimes been ccnsidered as one of the Isidinx.

Of the curious solitary Alcyonarians, the Haimeidæ, which up to now are known as small specimens from the Red Sea and from Algiers, a species of a very considerable size has been met with. Amphianthus, an absolutely flat Actinian, was found on the shell of a Dentalium, and amongst the numerous Echinoderm-finds material abounds to definitely settle the question about the regeneration and the so-called comet forms of Linckia. It could be demonstrated that the regeneration takes place, without any part of the disc being preserved, from a bare arm-frag. ment. On these Linckias the parasitical molluscs, Thyca and Stylifer, were often present. Various Solenogastres were captured, and many interesting Cephalopods. The fish collection is also very considerable, and a great many deep-sea forms are among them, of which a specimen of Ruvettus attains to a size of several feet.

The most beautifully transparent larval Murænas were at the other end of the scale, and were also exhibited at the meeting. Both they and other pelagic organisms, Medusæ, Heteropods, \&c., were most successfully preserved in formalin. On the whole the preservation of all the specimens, for which the most various methods were employed, is first-rate; and $\mathrm{Mr}$. Nierstrasz, to whose supervision this had been more especially entrusted, received due recognition of his merits on this head. Some hundred bottles of plankton have yet to be sorted and worked out. Dr. Versluys communicated to the meeting the results of investigations into the amount of oxygen contained in the sea-water at different points which he had made during the cruise, and Prof. Weber called attention to certain hydrographical results of primary importance obtained by the expedition.

The gist of these is that the communication between the deep water of the Indian and Pacific Oceans and that of the Archipelagan basins is very different from what it was expected to be. The different straits between the lesser Sunda Islands, Bali to Flores, are none of them deep enough to allow of any horizontal passage of the deeper and colder strata (where the temperature is $0.9^{\circ} \mathrm{C}$.) into the Banda basin and its continuations between Flores and Timor and between Flores and Celebes. These undoubtedly receive their cold bottom-water from the Pacific Ocean by way of the deep communications indicated on the map to the north of Buru (the so-called Ceram sea), which opens out into the Pacific by a narrow passage (the so-called Moluccan passage). In the deep spurs, to which the name of Bali and Flores sea may be given, the expedition could actually demonstrate the existence of a bottom-current which flows westward and which brings the cold water from the Banda sea into these recesses where the supply from the Indian Ocean through the numerous straits is only superficial and restricted to surfacewater of a temperature of more than $12^{\circ} \mathrm{C}$. The cold bottom. current of $3^{\circ} \mathrm{C}$. just alluded to, which slowly flows westward out of the Banda sea, even rises up along the sloping coasts of the Kangeang-Paternoster-Postillon islands (not indicated on the map) situated north of this deep sea spur, as could be demonstrated both by serial temperatures and even by the net, which, as mentioned above, brought up deep-sea forms from comparatively shallow water, just because of this bottom current, which, being hemmed in, flows towards the surface.

The temperature of $3^{\circ} \mathrm{C}$. referred to above is the uniform minimum temperature for the whole of the Banda basin below the depth of $1600 \mathrm{~m}$., and the theoretical conclusion that no deeper communications than this exist with either of the Oceans was practically verified, and also (as indicated above) that the cold water of the greater depths comes from the Pacific and not from the Indian Ocean.

The Banda Sea, sensu strictiori, was further found to be different from what was hitherto held. On charts, mention is made of a depth of 7000 metres (4000 fathoms) in the neighbourhood of Banda. This depth has been demonstrated by the Siboga to be due to some error, the depth being nowhere below 5500 metres, and the basin itself being most unexpectedly intersected by two shallow ridges, clearly visible on the map, the more westward of which has been named the Siboga Ridge. Geological speculations concerning this part of the earth's crust will undoubtedly be influenced by these results.

For the distribution of deep-sea animals, the difference of a couple of degrees between the bottom-water of these basins and that of the oceans will certainly not have much importance; and even the ridges will in the long run prevent only very few deep-sea animals from penetrating into the basins in the course of generations, when the difference of pressure can be slowly neutralised. At all events, the catches did not justify expectations that these enclosed deep basins might harbour a deep-sea fauna which, by its isolation from the ocean, had developed into peculiar local deep-sea faunas particular to those basins.

The hydrographical work of the expedition has thus been of very considerable importance, and will soon be also noticeable in improved navigating charts for the regions explored. Even geographical corrections of considerable amount are amongst the results of the cruise. The south coast of the large island of Timor (of which the eastern half is a Portuguese, the western a Dutch possession) will have to undergo a radical alteration, as indicated on the accompanying sketch (Fig. 2). Thus the Siboga expedition has not inconsiderably reduced the colonial surface area of Portugal, having anchored in spots which, according to the present maps, lie far inland.

The expedition can thus be complimented on having achieved a most successful piece of work, and it is undoubtedly in the first place due to the undaunted energy of the leader, Prof. Weber, and to the exemplary skill of the officer in command of the vessel, Comm. Tydeman, who for many years has already been one of the leading hydrographers in the Archipelago. The liberality of the Naval Department, and its active co-operation in all that pertained to the expedition, have been especially noticeable.

The results, toth hydrographical, botanical, zoological and geological, will, as soon as possible, be worked out by different

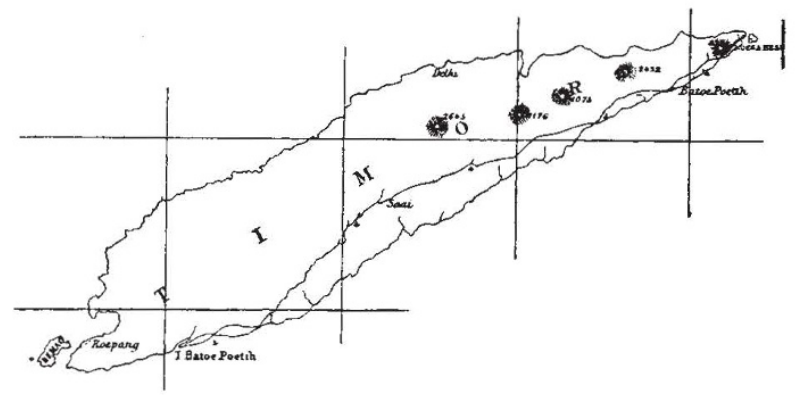

FIG. 2.-The coast-line of Timor. The outside southern coast-line is as indicated upon current maps; the inner line shows the true coast-line as determined by the Siboga.

specialists, and be brought together in a series of well-illustrated quarto volumes, the number of which is roughly estimated at about fifteen. Several specialists, both Dutch and foreign, have aiready promised to co-operate, and what with Alcock's researches in the Bay of Bengal, the Valdivia's exploration of the Indian Ocean, the Australian investigations of the Barrier Reef and the Torres Straits, the Belgian Antarctic expedition, and Agassiz's dredging expeditions in the Pacific, we can safely say that, by the time this publication will have appeared, we will have obtained a very thorough knowledge of an important portion of the abyssal regions, towards the exploration of which the Lightning, Porcupine and Challenger have set the example, and the Blake, Albatross, Travailleur, Talisman, Gazelle, Vettor Pisani, Willem Barents, Hirondelle and Princesse Alice have so considerably contributed from other parts of the globe.

A. A. W. H.

\section{EXPERIMENTATION ON EMOTION.}

$\mathrm{O}^{\mathrm{F}}$ points where physiology and psychology touch, the place of one lies at the phenomenon "emotion." Built upon sense-feeling much as cognition is built upon sense-perception, emotion may be regarded almost as a "feeling "-a "feeling" excited, not by a simple unelaborated sensation, but by a group or train of ideas. To such compound ideas it holds relation much as does "feeling" to certain species of simple sense-perceptions. It has a special physiological interest in that certain visceral reactions are peculiarly concomitant with it. Heart, blood-vessels, respiratory muscles and secretory glands

NO. 1605, VOL. 62] 
play special and characteristic róles in the various emotions. These viscera, though otherwise remote from the general play of psychical process, are affected vividly by the emotional. Hence many a picturesque metaphor of proverb and phrase and name-" the heart is better than the head," anger "swells within the breast," "Richard Cnur de Lion." It was Descartes who first relegated the emotions to the brain. Even this century Bichat wrote, "The brain is the seat of cognition, and is never affected by the emotions, whose sole seat lies in the viscera." But brain is now admittedly a factor necessary in all higher animal forms to every mechanism whose working has consciousness adjunct.

What is the meaning of the intimate linkage of visceral actions to psychical states emotional ? To the ordinary day's consciousness of the healthy individual the life of the viscera contributes little at all, except under emotion. The perceptions of the normal consciousness are rather those of outlook upon the circumambent universe than inlook into the microcosm of the "material me." Yet heightened beating of the heart, blanching or flushing of the blood-vessels, the pallor of fear, the blush of shame, the Rabelaisian effect of fright upon the bowel, the action of the lacrymal gland in grief, all these are prominent characters in the pantomime of natural emotion. Visceral disturbance is eridently a part of the corporeal expression of emotion. The explanation is a particular case in that of movements of expression in general. The hypothesis of Evolution afforded a new vantage point for study of that question. Fixed bodily expressions of emotion are hereditary. They are, especially in the "coarser or animal emotions," largely common to man and higher animals. The point of view is exemplified by Darwin's argument concerning the contraction of the muscles round the eyes during screaming. "Children when wanting food or suffering in any way cry out loudly like the young of most animals, partly as a call to their parents for aid, and partly from any great exertion serving as relief. Prolonged screaming inevitably leads to the engorging of the blood-vessels of the eye ; and this will have led at first consciously and at last habitually to the contraction of the muscles round the eyes in order to protect them." Mr. Spencer writes : "Fear, when strong, expresses itself in cries, in efforts to hide or escape, in palpitations and tremblings; and these are just the manifestations which would accompany an actual experience of the evil feared. The destructive passions are shown in a general tension of the muscular system, in gnashing of the teeth and protrusion of the claws, in dilated eyes and nostrils, in growls : and these are weaker forms of the actions that accompany the killing of prey." In a word, expression of emotion is instinctive action.

Movement of expression, be it facial or vocal, let it involve the skeletal or the visceral musculature, must have an explanation the same in kind as that of other instinctive movement. To enter upon its "why" is to enter upon the "why" of instinct. Suffice it to say here that if we follow the doctrine of evolution we cannot admit any absolute break between man and brute even in the matter of mental endowment. The instinctive bodily expressions of enotion probably arose as attitudes useful in the animal's environment for defence, escape, seizure, embrace, \&c. These as survivals have become symbolic for states of mind. Hence the intelligible nexus between the muscular attitude, the pose of feature, \&c., and the emotional state of mind. But between action of the viscera and the psychical state the nexus is less obviously explicable. This latter connection adds a difficult corollary to the general problem.

The fact of the connection is on all hands admitted, but as to the manner of it opinion is at issue. Does (I) the psychical part of the emotion arise and its correlate nervous action then excite the viscera? Or (2) does the same stimulus which excites the mind excite concurrently and per se the nervous centres ruling the viscera? Or (3) does the stimulus which is the exciting cause of the emotion act first on the nervous centres ruling the viscera, and their action then generate visceral sensations; and do these latter, laden with affective quality as we know they will be, induce the emotion of the mind? On the first of the three hypotheses the visceral reaction will be secondary to the psychical, on the second the two will be collateral and concurrent, on the third the psychical process will be secondary to the visceral.

To examine the last supposition first. It is a view which in recent years has won notable adherents. Prof. William James writes: "Our natural way of thinking about these coarser emotions (e.g. "grief, fear, rage, love") is that the mental perception of some fact excites the mental affection called the emotion, and that this latter state of mind gives rise to the bodily expression. My theory, on the contrary, is that the bodily changes follow directly the perception of the exciting fact, and that our feeling of the same changes as they occur is the emotion." " Every one of the bodily changes, whatsoever it be, is FELT, acutely or obscurely, the moment it occurs. If the reader has never paid attention to this matter, he will be both interested and astonished to learn how many different local bodily feelings he can detect in himself as characteristic of his various emotional moods." "If we fancy some strong emotion and then try to abstract from our consciousness of it all the feelings of its bodily symptoms we find we have nothing left behind, no " mindstuff" out of which the emotion can be constituted, and that a cold and neutral state of intellectual perception is all that remains." "If I were to become corporeally anæsthetic, I should be excluded from the life of the affections, harsh and tender alike, and drag out an existence of merely cognitive or intellectual form."

Prof. Lange traces the whole psycho-physiology of emotion to certain excitations of the vasomotor centre. For him, as f.r Prof. James, the emotion is the outcome and not the cause or the concomitant of the organic reaction; but for him the foundation and corner-stone of the organic reaction is as to physiological quality vascular, namely, vasomotor. Emotion is an outcome of vasomotor reaction to stimuli of a particular kind. This stimulus induces a vasomotor action in viscera skin, and brain. The change thus induced in the circulatory condition of these organs induces changes in the actions of the organs themselves, and these latter changes evoke sensations which constitute the essential part of emotion. It is by excitation of the vasomotor centre, therefore, that the exciting cause, whatever it chance to be, of emotion produces the organic phenomena which as felt constitute for Lange the whole essence of emotion. The teaching of l'rof. Sergi closely approximates to that of Lange.

The views of James, Lange, and Sergi have common to them this, that the psychical process of emotion is secondary to a discharge of nervous impulses into the vascular and visceral organs of the body suddenly excited by certain peculiar stimuli, and that it depends upon the reaction of those organs. Prof. James's position in the matter is, however, not wholly like that of Prof. Lange. In the first place, he does not consider vasomotor reaction to be primary to all the other organic and visceral disturbances that carry in their train the psychological appanage of emotion; and Prof. Sergi, though more nearly in harmony with Lange, agrees with James in this. In the second place, Prof. James seems to distinctly include other "motor" sensa. tions and centripetal impulses from musculature other than visceral and vascular, among those which causally contribute to emotion. Thirdly, he urges his theory as one completely competent only for the "coarser " emotions, among which he instances "fear, anger, love, grief." For Lange and Sergi the basis of apparition of all feeling and emotion is physiological, visceral, and organic, and has seat for the former authority exclusively, and for the latter eminently, in the vasomotor system.

To obtain some test of this view is not difficult by experiment. Appropriate spinal and vagal transection removes completely and immediately the sensation of all the viscera and of all the skin and muscles below the shoulder (see Fig. I on p. 330). The procedure at the same time cuts from connection with the organs of consciousness the whole of the circulatory apparatus of the body. I have had under observation dogs in which this had been carried out. I will cite an animal selected because of markedly emotional temperament. Affectionate toward the laboratory attendants, one of whom had her in charge, toward some persons and toward several inmates of the animal house she frequently showed violent anger. Her ebullitions of rage were sudden. Their expression accorded with a description furnished by Darwin. Besides the utterance of the growl, " the ears are pressed closely backwards, and the upper lip is retracted out of the way of the teeth, especially of the canines." The mouth was slightly opened and lifted; the eyelids widely parted; the pupils dilated. The hair along the mid-dorsum, from close behind the head to a point more than half way down the trunk, became rough and bristling.

The reduction of the field of sensation in this animal by the

NO. 1605, VOL. 62] 
procedure above-mentioned produced no obvious diminution or change of her emotional character. Her anger, her joy, her disgust, and when provocation arose her fear remained as evident as ever. Her joy at the approach or notice of the attendant, her rage at the intrusion of a cat with which she was unfriendly, remained as active and thorough. But among the signs expressive of rage the bristling of the coat along the back no longer occurred. On he other hand, the eyes were well opened, and the pupil distinctly dilated in the paroxysm of anger. Since the brain had been by the transection shut out from discharging impulses via the cervical sympathetic the dilatation of pupil must have occurred by inhibition of the action of the oculomotor centre.

The coming of a visitor whose advent months before had elicited violent anger, again provoked an exhibition of wrath sig nificant as ever. The expression was that of aggressive rage. The animal followed each movement of the stranger as though of an opponent, growling viciously. A cat with which she was never friendly, and a monkey new to the laboratory, approaching too near the kennel, excited similar ebullitions. No doubt was left in our minds that sudden attacks of violent anger were still easily excited. But she also gave evidence daily that she had the accession of joyous pleasure and delight she had always shown at the approach of the attendant the first thing of a morning, or at feeding time, or when caressed by him, or encouraged by his voice.

Few dogs even when very hungry can be prevailed on to touch dog's-flesh as food. Almost all turn from it with signs of repugnance and dislike. I had strictly refrained from testing

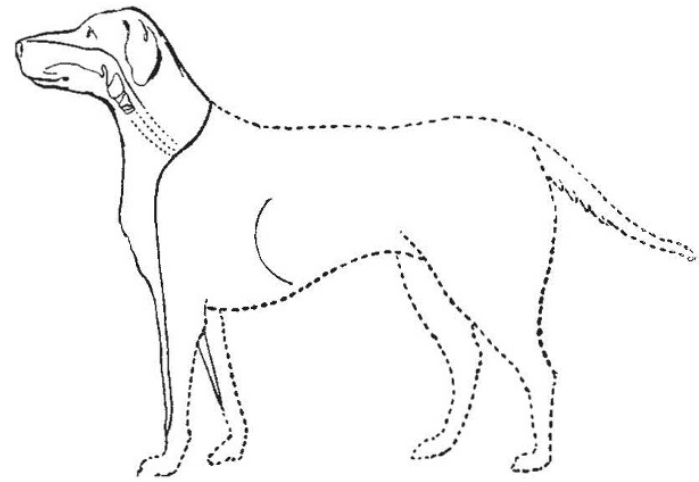

FIG. x.-Diagram showing the great reduction of the field of sentivity. The head and neck and the diaphragm muscle (indicated by the curved line behind the chest) are practically the only parts left sensitive. The remainder of the body and the limbs, as well as the digestive and respiratory organs behind the throat, and the whole of the circulator and other organs, are entirely cut off from making any contribution to

this animal previously with regard to disgust at dog's-flesh offered in her food. Flesh was given her daily in a bowl of milk, and this she took with relish. The meat was cut into pieces rather larger than the lumps of sugar usual for the breakfast table. It was generally horse-flesh, sometimes oxflesh. We proceeded to the observation thus: the bowl was placed by the attendant in the corner of the stall, with milk and meat in every way as usual; but the meat was flesh from a dog killed on the previous day. Our animal eagerly drew itself toward the food; it had seen the other dogs fed, and evidently itself was hungry. Its muzzle had almost dipped into the milk before it suddenly seemed to find something there amiss. It hesitated, moved its muzzle about above the milk, made a venture to take a piece of the meat, but before actually seizing it stopped short and withdrew again from it. Finally, after some further examination of the contents of the bowl (it usually com menced by taking out and eating the pieces of meat), without touching them, the creature turned away from the bowl and withdrew itself to the opposite side of the cage. Some minutes later, in result of encouragement from us to try the food again, it returned to the bowl. The same hesitant display of conflicting desire and disgust was once more gone through. The bowl was then removed by the attendant, emptied, washed, and horseflesh similarly prepared and placed in a fresh quantity of milk was offered in it to the animal. The animal once more drew

NO. 1605 , vOL. 62$]$ itself toward the bowl, and this time began to eat the meat. soon emptying the dish. To press the flesh upon our animal was of no real avail on any occasion; the coaxing only succeeded in getting her to, as it were, re-examine but not to touch the morsels. The impression made on all of us by the dog's behaviour was that something in the dog's-flesh was repulsive to her, and excited disgust unconquerable by ordinary hunger. Some odour attaching to the flesh seemed the source of its recognition.

Fear appeared clearly elicitable. The attendant, approaching from another room of which the door was open, chid the dog in high scolding tones. The creature's head sank, her gaze turned away from her advancing master, and her face seemed to betray dejection and anxiety. The respiration became unquiet, but the pulse never changed its rate.

In the face of these observations the vasomotor theory of the production of emotion becomes, I think, untenable: also that visceral sensations or presentations are necessary to emotion. A mere remnant of all the non-projecting or affective senses was left, and yet emotion persisted. If I understand it aright, Prof. James and Lange's theory lays stress on organic and visceral presentations, but re-presentations of the same species might no doubt be put forward in their place. That would be a somewhat different matter. To exclude the latter hypothesis, the deprivation of vascular and organic sensation might have to date from a very early period of the individual life. Experience early acquires its emotional data. If after that all fresh presentation were precluded, re-presentation might still be possible on the basis of already gained experience. But it is noteworthy that one of the dogs under observation had been deprived of its sensation when only nine weeks old. Disgust for dog's flesh could hardly have genesis in the experience of nine weeks of puppy life in the kennel of the laboratory.

Organic and vascular reaction, though not the actual excitant of emotion, does nevertheless much strengthen it. That is part of the kernel of the old contention about the strength of emotion in the art of the artist. Hamlet's description of the actor, as really moved by his expression, may be accepted as an answer.

But, returning to the main question, we are forced back toward the likelihood that the visceral expression of emotion is secondary to the psychical state, or rather to the cerebral nervous action correlate with that. There is plenty of evidence of the strong nexus between emotion and muscular action. As we commonly phrase it, "emotion moves us," hence the word itself. Emotion if developed in intensity, impels toward vigorous movement. Every vigorous movement of the body, though its more obvious instrument be the skeletal musculature of the limbs and trunk, involves also the less noticeable co-operation of the viscera, especially of the circulatory and respiratory. The demand made upon the muscles that move the frame for further expenditure of power involves a heightened action of the nutrient organs which supply to the muscles their material for energy. This increased action of the viscera is therefore colligate with this activity of muscles. We should therefore expect visceral action to occur along with the muscular expression of emotion. The close tie between visceral action and states of emotion need not therefore surprise us.

That emotion is primarily a cerebral process obtains support from observations where the hemispheres of the brain have been removed. Prof. Goltz observed a dog kept many months in that condition. It on no occasion gave any evidence of joy or pleasure in commerce either with man or beast. Anger or displeasure, Goltz says, it repeatedly expressed, both by gesture and by voice. Of sexual emotion it never gave a sign. Save for expression of displeasure when too roughly handled, it was indifferent and supremely neutral to its surroundings. We are, of course, in observations whose basis is such experiment as this, hopelessly cut off from introspective help. It can be urged that the expression of emotion might be provocable, and nevertheless the psychical emotion remain absent. On such an hypothesis the same stimulus which excites the mind must excite concurrently and per se excite motor centres producing movement appropriate to an affective process in the mind. This is not improbable. All sensations referred to the body itself rather than interpreted as qualities of objects in the external world, tend to be tinged with "feeling." Sense organs which initiate sensations tinged with feeling tend to excite motor centres directly and imperatively. Hence, in animals reduced to merely spinal condition, stimuli calculated to produce pain normally (of course, unable to do so in a spinal animal 
incapable of consciousness), evoke movements appropriate for escape from or removal of the stimulus applied. Now "feeling" is implicit in the emotional state; the state is an " affective state." In the evolution of emotion the revival of "feelings" pleasurable and painful must have played a large part. Hence the close relation of emotion with sense organs that can initiate bodily pain or pleasure, and hence its connection with impulsive or instinctive movement. There is no wide interval between the reflex movement of the spinal dog, whose foot attempts to scratch away an irritant applied to its back-both leg and back absolutely detached from consciousness-and the reaction of the decerebrate dog that turns and growls and bites at the fingers holding his hind foot too roughly. In the ormer case the motor reaction occurs, although the mind is not even aware of the stimulus, far less percipient of it as an irritant. The action occurs, and plays the pantomime of feeling ; but no feeling comes to pass. In the latter case the motor reaction occurs, and is expressive of emotion; but it is probably the reaction of an organic machine, which can be started working, though the mutilation precludes the psychosis of emotion.

And with the gesture and the attitude will occur the visceral concomitant. It would be consonant with what we know of reflex action if the spur that started the muscular expression should simultaneously and of itself initiate, also, the visceral adjunct reaction. It is almost impossible to believe that with the mere stump of brain that remained to Goltz's dog there could be any elaboration of a percept. All trace of memory was lacking to the creature. Yet though not evincing other emotion, anger it showed as far as expression can yield revelation. Fear, joy, affection seem, therefore, in the observation of this skilled observer of animal mind, to demand higher nervous organisation than does anger. $\mathrm{Be}$ that as it may, the retention of its expression by Goltz's dog indicates that by "retrogradation" the complex movement of expression has in certain emotions passed into a simple reflex act. When the habituating practice of acts is carried far the determining motives finally become, even in impulsive acts, weaker and more transient. The external stimulus originally aroused a strongly affective group of ideas, which operated as a motive, but now it causes a discharge of the act before it can be apprehended as an idea. The impulsive movement of a "lower," "coarser," socalled " animal" emotion, has in this case become an automatic reflex process no longer necessarily combined with the psychical state whence it arose, of which it is normally at once the adjunct and the symbol.

C. S. Sherrington.

\section{THE CENTENARY OF THE ROYAL COLLEGE OF SURGEONS.}

$M R$. VICTOR PLARR'S article, in last week's NATURE, on the celebration of the centenary of the Royal College of Surgeons of England contained a brief statement of the ceremonies which were to commence on the day we went to press. The proceedings were opened on Wednesday inorning, July 25 , when demonstrations were given in the Hunterian Museum of the College by the conservator, Prof. C. Stewart, F.R.S., who conducted visitors round the galleries, pointing out and describing some of the more important and interesting specimens. At the same time, in the theatre of the Examination Hall, Dr. T. G. Brodie, director of the laboratories of the Conjoint Board, gave an account of some of the work recently carried out in the research laboratories. In the evening a conversazione was held at the College, and was attended by many distinguished guests. Demonstrations were again given by Prof. Stewart and Dr. Brodie on Thursday morning; and in the afternoon, Sir William MacCormack, the president, delivered an address of welcome, and presented the diploma of Honorary Fellow to the Marquis of Salisbury and the Earl of Rosebery. As already stated (p. 294), the Prince of Wales received the diploma on July 24; and the form of the Royal diploma is the same as that employed for all the Honorary Fellowships.

The following is the list of other Honorary Fellows to whom diplomas were presented on Thursday :-E. Albert, professor of clinical surgery, University of Vienna ; C. B. Ball, Regius professor of surgery, University of Dublin ; E. Bassini, professor of clinical surgery, Royal University of Padua ; E. H. Bennett, professor of surgery, Trinity College, Dublin; J. W. Berg, professor of surgery, Royal Caroline Institute of Medicine and Surgery, Stockholm ; Prof. von Bergmann, Berlin; O. Bloch, professor No. I605, VOL. 62] of surgery, University of Copenhagen ; E. Bottini, professor of clinical surgery, Royal University of Pavia; I. II. Cameron, professor of clinical surgery, University of Toronto; Dr. Salvador Cardenal Fernandez, vice-president, Royal Academy of Medicine and Surgery, Barcelona; Antonino D'Antona, professor of surgery, Royal University of Naples; Francesco Durante, professor of clinical surgery, Royal University of Rome : Prof Dr. Friedrich von Esmarch Kiel ; W. S. Halsted, professor of surgery, Johns Hopkins University, Baltimore; Hon. Sir W. H. Hingston, professor of clinical surgery, University of Laval; Surgeon-General James Jameson, C.B., Director-General, Army Medical Service ; W. W. Keen, professor of the principles of surgery and of clinical surgery, Jefferson Medical College, Philadelphia; Theodor Kocher, professor of surgery, University of Bern ; Prof. Dr. Franz König, Berlin ; Prof. Kosinskij, professor of surgery in the University of Warsaw Prof. Dr. E. G. F. Kïster, Marburg ; Elie Lambotte, Brussels Odilon Marc Lannelongue, professor of surgical pathology, Facuity of Medicine of Paris; Karl Gustaf Lennander, pro fessor of surgery and obstetrics, University of Upsala; W. Macewen, F.R.S., Regius professor of surgery, University of Glasgow; Colonel Kenneth MacLeod, professor of clinical and military medicine, Army Medical School, Netley; Julius Nicolaysen, professor of surgery, Royal University of Chris tiania ; Sir Henry Frederick Norbury, K.C.B., Director-General, Medical Department of the Royal Navy; Leopold Ollier, professor of clinical surgery, University of Lyons; Victor Pachou. tine, president, Imperial Military Academy of Medicine, St. Petersburg; Samuel Pozzi, professor in the Faculty of Medicine of Paris; Colonel D. C. O'Connell Raye, Indian Medical Service; T. G. Roddick, professor of surgery, McGill University, Montreal; Federico Rubio y Gali, member of the Royal Academy of Medicine of Madrid; Nicolas Wassilievitch Sklifossovsky, director and Emeritus professor, Imperial Clinical Institute of the Grand Duchess Helena Pavlovna, St. Petersburg; Paul Tillaux, professor of clinical surgery, Faculty of Medicine of Paris; Nicolas Veliaminoff, professor of surgery. Imperial Military Academy of Medicine, St. Peters. burg; John Collins Warren, professor of surgery, Harvard University; Robert Fulton Weir, professor of clinical surgery, Columbia University, New York. After the presentation brief addresses of thanks were delivered by Prof. v. Bergmann of Berlin, Prof. Durante of Rome, Dr. W. W. Keen of Philadelphia, Prof. Lannelongue, and Dr. T. G. Roddick of Montreal.

\section{FACTS OF INHERITANCE. ${ }^{1}$}

$\mathrm{NE}$ of the distinctive features of the nineteenth century has been a reduction in the number of supposed separate powers or entities-the use of William of Occam's razor, in fact. In view of this progress towards greater precision of phraseology, it cannot be a matter for surprise that a biologist should affirm that to speak of the "Principle of Heredity" in organisms is like speaking of the "Principle of Horologity" in clocks. For heredity is certainly no power or force, or principle, but a convenient term for the relation of organic or genetic continuity which binds generation to generation.

Another distinctive feature in scientific progress has been the introduction of precise measurement. In the development of natural knowledge, science begins where measurement begins. This is the case in regard to inheritance. While nothing can take the place of experiment, much has been gained by the application of statistical and mathematical methods to biological results-a new contact between different disciplines-which we may particularly associate with the names of NIr. Francis Galton and Mr. Karl Pearson.

\section{The Physical Basis of Inheritance.}

What was for so long quite hidden from inquiring minds, or but dimly discerned by a few, is now one of the most marvellous of biological commonplaces - that the individual life of the great majority of plants and animals begins in the union of two minute elements - the sperm-cell and the egg-cell. If inheritance includes all that the living creature is or has to start with in virtue of its genetic relation to its parents and ancestors, then it is

1 Abridged from a discourse delivered at the Royal Institution on Friday, March 30, by Prof. J. Arthur Thomson, F.R.S. 